\title{
The role of social media in delivering news related to the COVID-19 pandemic: Moroccan community as a case study
}

\author{
Nezha Mejjad ${ }^{1 *}$, Hanane Yaagoubi, Mourad Gourmaj ${ }^{3}$, Aniss Moumen ${ }^{4}$, Nabil \\ Chakhchaoui ${ }^{5,6}$, Rida Farhan ${ }^{5,7}$ Md. Rakib Refat Jahan ${ }^{8}$, \\ ${ }^{1}$ Laboratory of Applied Geology, Geomatics and Environment- Faculty of Sciences - Ben M'sik, B.P \\ 7955, 20670. Casablanca, Morocco. \\ ${ }^{2}$ Laboratory of Applied Mechanics and Technologies (LAMAT), ENSET, STIS Research Center \\ Mohammed V University, Rabat, Morocco. \\ ${ }^{3}$ MATIC team, Sultane Moulay Slimane University in Beni Mellal, Morocco. \\ ${ }^{4}$ National School of Applied Sciences-Kenitra, University of Ibn Tofail. Kénitra, Morocco. \\ ${ }^{5}$ Laboratoire Nanotechnologies et Nanosystèmes, LN2, CNRS, Université de Sherbrooke,3IT (Institut \\ Interdisciplinaire d'Innovation Technologique), Sherbrooke, QC, Canada. \\ ${ }^{6}$ REMTEX Laboratory, Higher School of Textile and Clothing Industries (ESITH), Casablanca Morocco. \\ ${ }^{7}$ Laboratory of Physics of Condensed Matter (LPMC), Faculty of Sciences Ben M'Sick, Hassan II \\ University of Casablanca, Morocco. \\ ${ }^{8}$ Department of Fisheries and Marine Science, Faculty of Science, Noakhali Science and Technology \\ University, Bangladesh.
}

\begin{abstract}
The study aims to assess the Moroccan community's using rate of social media, especially during the imposed lockdown, and analyze how the community is using and exploring the news published on Facebook. In this order, we prepared and shared a survey questionnaire among Facebook, Twitter and WhatsApp users. The obtained responses exhibit that only 5\% of respondents share the news immediately without verifying the source, while $54 \%$ share news only after verifying the source; the rest did not prefer to share COVID-19 related news. This may reflect the awareness level of the sampled population about the importance of verifying the source of information before sharing it, especially during such conditions. However, $64 \%$ of participants think that Social Media platforms are not sufficient and appropriate to warn and inform the population about this sanitary crisis as not all Moroccan citizens have access to the internet and do not use social media. Besides, the COVID-19 period has known a rapid spread of misinformation and fake news through these platforms, impacting community mental health. Although, it is recommended to consider warning people about the best practices and use of shared information through these platforms
\end{abstract}

\section{Introduction}


The outbreak of COVID-19 is the most discussed topic in social media since December 2019, and the concern about this dangerous virus influence on human beings has increased drastically when its propagation has reached European and American countries. Accordingly, several safety measures were taken worldwide, and all the social media platforms have participated actively in delivering information and news about the rate of growth of the virus. In addition, these online platforms have played a crucial role as a marketing tool during the COVID-19, which changed the marketing strategies as reported in [1].

Although Facebook is currently the most visited platform because all the news related to COVID-19 are published on official Facebook pages of the health ministry of almost all countries, thus social media links the community to competent authorities. Accordingly, professional and personal lives have been merged by online platforms such as Twitter, Facebook and Instagram [2] where these platforms have played a crucial role in maintaining communication with family and friends, which helped reduce the isolation caused by COVID-19.

The outbreak of COVID-19 has affected education [3-4], the economy [5], the environment [6-9] and political relations [10-12], among others. In addition, numerous studies were focused on the social media role during the COVID-19 on delivering information, enhancing awareness and even as platforms for knowledge acquisition [13-18].

Almotawa and Aljabri, 2020 [19] confirmed that social media is a practical and useful tool as a source of information for COVID-19. Obi-Ani et al., 2020 [20] also agree that social media are efficient and prompt in delivering information and keeping up communication surrounding the pandemic.

In the present study, we analyze how Moroccan communities behave toward the COVID-19 news posted on Social Media platforms and if it helps spread or prevent panic among people.

\section{Methods and Materials}

\subsection{Study design}

We review and analyze the role of social media platforms in disseminating information among communities during COVID-19. The study will be focused mainly on the Moroccan community, especially during the imposed lockdown. We investigate the Moroccan usage of social media platforms during the COVID-19 and, more precisely, Facebook as it is the most popular platform used by the Moroccan community compared to other social networks. It was reported that $82.34 \%$ of the Moroccans connected to the internet had used Facebook during August 2020, according to Statcounter [21].

\subsection{Data: Population \& Survey questionnaire}

An online survey was carried out from 04 April to 13 May 2020 to investigate the Moroccan community usage of social media platforms during the COVID-19 and their impacts on community psychology well-being. It was impossible to perform a survey in the field because of the taken safety measures by Moroccan authorities. Accordingly, to avoid any type of contact with infected persons, the survey questionnaire was answered through social networks channels (Facebook, Twitter, Instagram, and WhatsApp) and email. A total of 282 respondents have answered the exploratory survey.

The survey was based on the following parts:

i) First part about the general information of surveyed people (Gender, Age, city,

Education level, and employment sector); 
ii) Second part concerns the subscription to Facebook pages and official pages of the newspaper.

iii) Third part was related to the verification of the source of data and information shared in social media platforms and their sufficiency as a source of information;

iv)The last part was devoted to analyzing the participant's feelings toward the daily shared news about COVID-19. All the participants were informed about the confidentiality of their answers and the purpose of conducting this questionnaire survey.

\section{Results}

\subsection{Social networks and covid19}

The obtained responses according to gender mainly were answered by women, indicating that the Facebook platform is mainly used by women ( 86.1 women and $13.9 \%$ men). Almost all the respondents are students, $\mathrm{PhD}$ and university professors, which could be linked to their daily internet usage for study and scientific research purposes.

\subsubsection{Disseminating news via Social Media platforms}

The survey questionnaire was focused on understanding if the Moroccan community is sharing information after verifying the source and trusting the news pages and media that are following.

The obtained responses indicate that almost all respondents follow Medias and Facebook pages to keep updated about the COVID-19 related information and news (Figure 1). This suggests that Facebook is currently a major source of information and consequently a useful tool helping increase community adherence to safety measures. However, Facebook can also be a source of panic, fake news or data, and a tool for spreading misinformation reported in many studies [17, 20, 22].

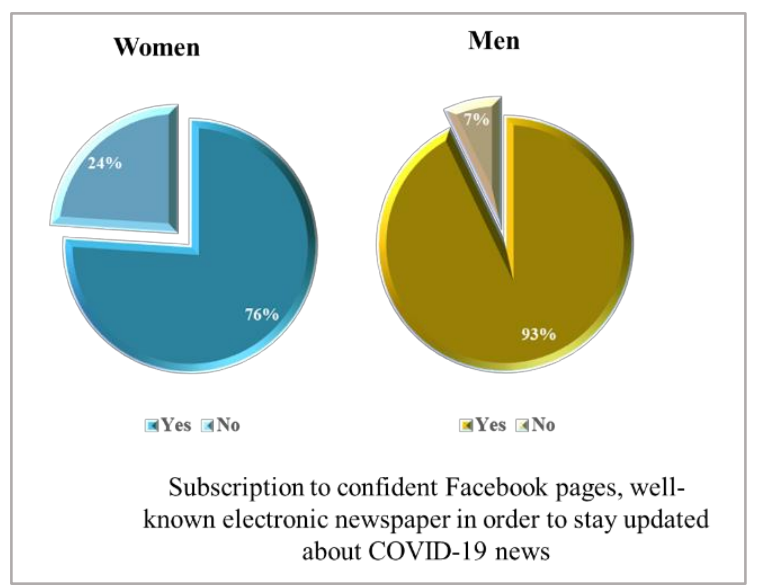

Fig.1. Percentage of respondents subscribed to Facebook pages and electronic newspapers.

In Figure 2 and Table 1, we analyze if the Facebook pages followers verified the information before sharing it or sharing it immediately without checking the source. 
The obtained response showed that more than half of respondents share information after verifying the source, while $41 \%$ only read information without verifying or sharing it. $5 \%$ are sharing COVID-19 related news directly without checking the source. This result may indicate that the respondents are aware that such platforms are sometimes used to disseminate fraud, fake news, and messages. The COVID-19 impact on human mental health was widely studied, especially with the COVID-19 onset and during the lockdown period. Hammad and Alqarni [23] have found a close relationship between the widespread misinformation via social media and mental health symptoms such as depression, anxiety, and social isolation. In contrast, some studies linked these mental health symptom prevalence with the imposed lockdown caused by COVID-19 [24-26]. Jannati Idrissi et al. [27] reported a high prevalence of sleep disorders, depressive symptoms and anxiety within the Moroccan population during the imposed lockdown associated with COVID-19. The same observation was reported in a study based on a survey carried out on a population sample from Arabia Saudi, where onefourth of respondents have experienced moderate to severe psychological impact during the early stage of the COVID-19 [28].

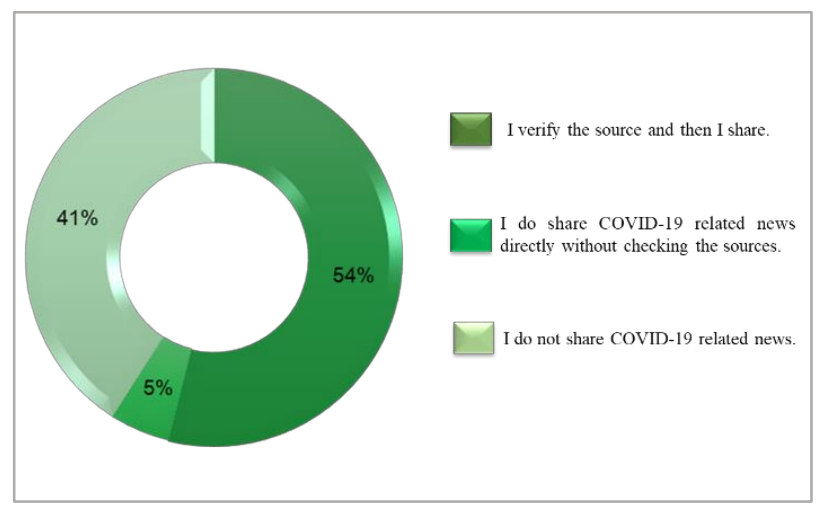

Fig.2. \% of respondents that verify the COVID-19 news source before sharing them.

We compared the percentage of men and women subscribed to confident Facebook pages and electronic newspapers, with the percentage of respondents verifying the COVID-19 news source before sharing them (Table 1). The results indicate that almost all respondents share information after checking the source or do not share the COVID-19 related news. This finding may reflect the awareness level of the sampled population about the importance of verifying the source of information before sharing it, especially during such conditions. In addition, these results may reflect the Moroccan community responses to the authorities call (on 04 March 2020) to be cautious about the broadcast and diffusion of fake news related to COVID-19 while firm instructions were given to courts across the country to take legal action against anyone disseminating false news about the COVID-19 [29].

Table 1: Percentage (\%) of respondents sharing COVID-19 related news with and without checking the source according to gender type.

\begin{tabular}{|c|c|c|c|}
\hline & $\begin{array}{c}\text { I verify the } \\
\text { source, and } \\
\text { then I share }\end{array}$ & $\begin{array}{c}\text { I do share COVID-19 } \\
\text { related news directly } \\
\text { without checking the } \\
\text { sources }\end{array}$ & $\begin{array}{c}\text { I do not share } \\
\text { COVID-19 } \\
\text { related news }\end{array}$ \\
\hline Men & 40 & 8 & 52 \\
\hline Women & 59 & 5 & 36 \\
\hline
\end{tabular}




\subsubsection{Is Social Media a sufficient tool for disseminating information to the citizenry?}

We investigated the sampled population point of view toward the sufficiency of Facebook on disseminating news related to the COVID- 19 . The results indicate that $64 \%$ of respondents disagree with considering social media as the only sufficient tool to deliver information and updates about the subject of the COVID-19 health crisis, while $36 \%$ agree with this statement. This disagreement could be related to access to the internet and social media use and manipulation. According to the International Telecommunication Union (ITU), in 2019 [30], $74.37 \%$ of the Moroccan population are using the internet while $46.86 \%$ use Facebook, $36.91 \%$ utilizing YouTube, and only $11.79 \%$ employing Twitter by June 2021 [21]. Thus, we can understand the respondents who disagree with considering social networks as a sufficient tool to address COVID-19 related updates as not all Moroccan populations have access to the internet, and more than $50 \%$ are not using social networks. This disagreement could also be explained by widespread misinformation and false news related to coronavirus in the early stage of COVID-19 spread, which decreases social media users' confidence in shared news and information on these platforms.

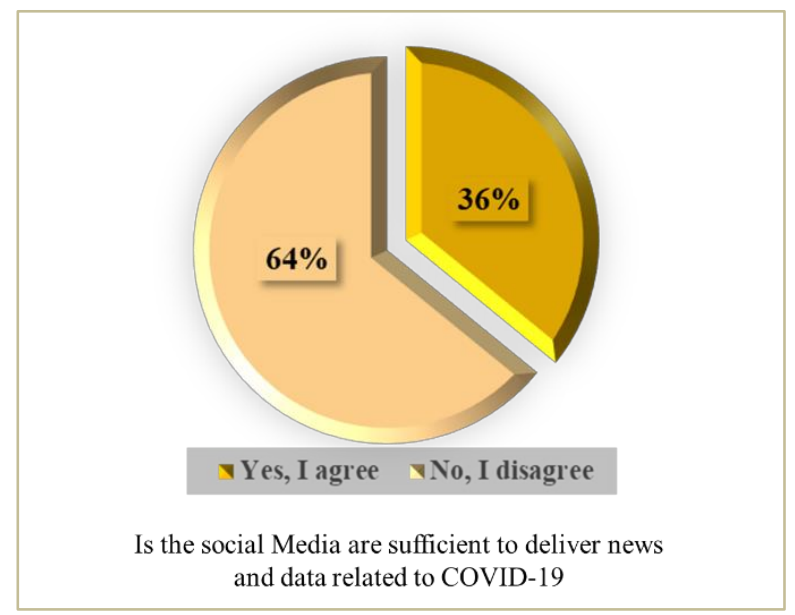

Fig.3. \% of respondents that agree and disagree about the Social Media sufficiency on disseminating COVID-19 news.

\subsubsection{Increasing awareness disseminating and sharing news through social media platforms and among family and friends}

As mentioned above, not all Moroccan population are using social media. This could be linked to the lack of access to the internet or because they do not know how to use these platforms or are not interested in such a social network. In this order, we asked our respondents (and Social Media users) if they are active in Social Media platforms and are helping increase awareness among their family and friends by sharing and disseminating all COVID-19 related news and information.

The results exhibited that $52 \%$ share news and information related to the COVID-19 with their family and friends to increase awareness about sanitary and safety measures. $48 \%$ are against sharing COVID-19 related news, and some of the respondents do not prefer to disseminate news because they think there is enough information and data on social networks platforms. 


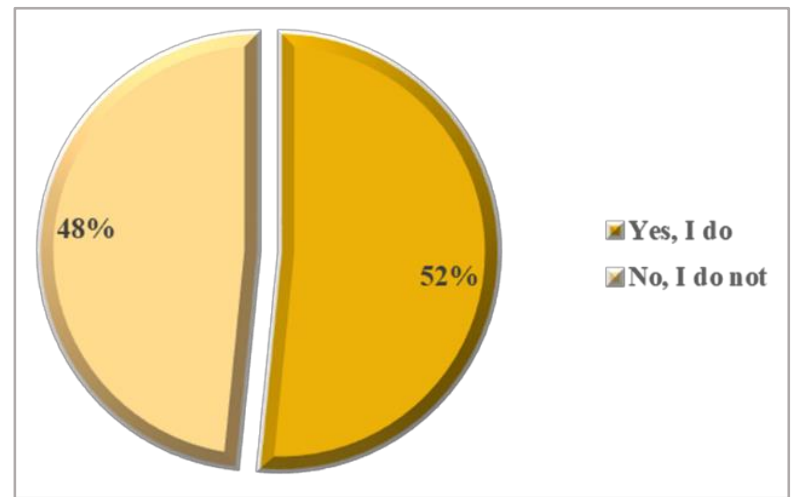

Fig. 4. Percentage of respondents do not and do prefer to share news among their family and friends.

\subsection{Social Media platforms impact on community mental health during COVID- 19}

In order to understand how the sampled population received the news related to COVID-19, including the spreading rate of virus and number of daily recorded cases in Morocco, we asked them about their feelings when they receive COVID-19 news notifications.

A percentage of 54 respondents indicated that reading news related to COVID-19 cause them stress and scare them, while $38 \%$ said that reading this news has no impact on them and their mental health (e.g. stress, panic ..). These results may reflect the indirect impact of social media on community mental health, especially if the shared and posted news are unverified or contain misinformation and fake data. This result is in good accordance with Ahmad and Murad's 2020 [16] study, where the respondents have reported that social networks significantly impact spreading panic and fear among Iraqi Kurdistan during the COVID-19 outbreak, potentially negatively affecting community mental health.

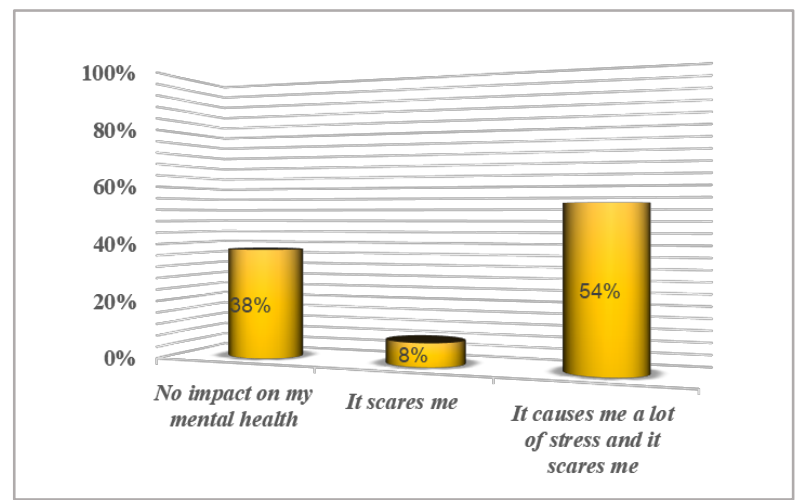

Fig. 5. The respondent's feelings related to COVID-19 daily news.

\section{Conclusion}

We conclude that social media, including Facebook, has an interesting role in providing information to its users, which allows them to share related news, and information with their family and friends. Despite the fake news published every day, even every hour, these platforms currently play a major role in transmitting news and information. 
In this order, we would like to highlight the need for considering increasing awareness among social media users regarding posting and sharing news without verifying the sources. In addition, it is necessary to warn and advise the community to follow the government and authorities' official pages and avoid the following, reading and sharing news and information from unverified social media pages.

\section{References}

1. A.N. Mason, J. Narcum, K. Cogent Business \& Management 8,1 (2020).

2. Eng Koon Ong, Chu Hsien Lim, Alexandra JTY Wong. Annals, Academy of Medicine, Singapore (2020).

3. S. Pokhrel and R. Chhetri. Higher Education for the Future 8, 1 (2021).

4. E. J. Baron, E. G. Goldstein, C. T. Wallace, J. Publ. Econ. 190, 104258 (2020).

5. D. Witteveen, E. Velthorst. Proc. Natl. Acad. Sci. U.S.A. 117, 27277-27284 (2020).

6. D. Suresh, A. Chauhan, N. Othmani, S. Bhadauria, J. Aswin, N. Jose, N. Mejjad. Preprint in Research square. (2020).

7. S.E. Sbai, N. Mejjad, A. Norelyaqine, F. Bentayab. Air QualAtmos Health 14, 617-628 (2021).

8. N. Mejjad, E.K. Cherif, A. Rodero, D.A. Krawczyk, J. El Kharraz, A. Moumen, M. Laqbaqbi, A. Fekri.Int. J. Environ. Res. Public Health 18, 4382 (2021).

9. E.K. Cherif, M. Vodopivec, N. Mejjad, J.C.G.E. Da Silva, S. Simonovǐc, H. Boulaassal. Water 12, 2638 (2020).

10. Bol, D, M Giani, A Blais and P J Loewen. Eur J Polit Res. 60, 2 (2020).

11. Herrera, H, M Konradt, G Ordoñez and C Trebesch. CEPR Covid Economics 50: 3-32 (2020).

12. Herrera, H, G Ordoñez and C Trebesch. Journal of Political Economy 128, 2 (2020).

13. M.N. Khan, M.A. Ashraf, D. Seinen, K.U. Khan, R.A. Laar. Front. Psychol. 12, 648253 (2021).

14. F. Gilardi, T.Gessler, M. Kubli, S. Müller. SPSR 27, 2 (2021).

15. C. Greenhow, A. Chapman. Inform. Learn. Sci. 121, 341-352 (2020).

16. A. R. Ahmad, H. R. Murad. J. Med. Internet Res. 22, 5 (2020).

17. W. Bukhari. Int J Front Sci. 4, 2 (2020).

18. H. Al-Dmour, R. Masa'Deh, A. Salman, M. Abuhashesh, R. Al-Dmour. J. Med. Internet Res. 22, 8 (2020).

19. T. Almotawa, D. Aljabri. ICEB 2020 Proceedings. 5-8 December 2020, Hong Kong.

20. N. A. Obi-Ani, C. Anikwenze, M. Chukwudi Isiani. Cogent Arts Humanit. 7, 1 (2020).

21. Statcounter. https://gs.statcounter.com/social-media-stats/all/morocco/2020) (2020).

22. J. Demuyakor. (IJHSS) 6, 5 (2020)

23. MA. Hammad, TM. Alqarni. PLos one 16, 3 (2021).

24. ML. Tee, CA. Tee, JP. Anlacan, KJG. Aligam, PWC. Reyes, V. Kuruchittham, RC. Ho. J Affect Disord. 1, 277 (2020).

25. C. Wang, R. Pan, X. Wan, Tan Y, Xu L, McIntyre RS, Choo FN, Tran B, Ho R, Sharma VK, Ho C. A Brain Behav Immun 87 (2020). 
26. MR. Gualano, G. Lo Moro, G. Voglino, F. Bert, R. Siliquini. Int J Environ Res Public Health 17, 13 (2020).

27. A. Janati Idrissi, A. Lamkaddem, A. Benouajjit, M. Ben El Bouaazzaoui, F. El Houari, M. Alami, S. Labyad, A. Chahidi, M. Benjelloun, S. Rabhi, N. Kissani, B. Zarhbouch, R. Ouazzani, F. Kadiri, R. Alouane, M. Elbiaze, S. Boujraf, S. El Fakir, Z. Souirti. Sleep Med. 74 (2020).

28. A.A. Alkhamees, S.A. Alrashed, A.A. Alzunaydi, A.S. Almohimeed, M.S. Aljohani. Compr Psychiatry. 102,152192 (2020).

29. Y. Madani, M. Erritali, B. Bouikhalene. Results in Physics 25, 104266 (2021).

30. The International Telecommunication Union (ITU), 2019 (in https://data.worldbank.org/indicator/IT.NET.USER.ZS?locations=MA). 